\title{
Administration via Hemodialysis
}

National Cancer Institute

\section{Source}

National Cancer Institute. Administration via Hemodialysis. NCI Thesaurus. Code C38200.

Method of administering the drug through hemodialysate fluid. 